\title{
Study of Techniques for Locating Public Transports using Vehicle Tracking Systems
}

\author{
Tushar B. Meshram \\ Computer Engineering \\ Lokamanya Tilak College of Engineering, \\ Navi Mumbai, India \\ Prof. Sujata Deshmukh \\ Computer Engineering \\ Lokamanya Tilak College of Engineering, \\ Navi Mumbai, India
}

\begin{abstract}
Vehicle tracking is a technique of finding the details of a vehicle like its current location, the time it will take to reach to its destination, its distance from the destination, its current speed etc. Two different techniques are applied to track the vehicle, one technique is using the Global Positioning System (GPS) which uses the set of satellites to locate the GPS device in the vehicle and the other technique uses the Base stations which determines the location based on the network of the mobile device in the vehicle and its nearest cell tower.

Time management is very important in today's high tech world, Everyone wants to reach to its destination on time. Now a day's nearly $80 \%$ of the worlds populations are travelling by the public transports but the Public transport users always remains in thought that whether they will reach to their destination on time or not, because public transports like buses may got late due to some environmental conditions or by the traffic. So if the Bus got late passengers have to unknowingly wait for the bus to arrive for the indefinite time.

There are many different techniques are used worldwide which uses the vehicle tracking system techniques to locate the vehicles, fleets of an organization etc. This papers looks into many different types of techniques used worldwide to track the vehicles.
\end{abstract}

Keywords - Vehicle tracking, Global Positioning System, Arrival time of the vehicle

\section{INTRODUCTION}

Vehicle tracking is a technique of finding the details of a vehicle like its current location, the time it will take to reach to its destination, its distance from the destination, its current speed etc.

A vehicle based tracking[20] joins the installation of the electrical device in the vehicle, or fleet of vehicles, with purposely-designed computer application enables the owner to track the vehicle location obtained from the vehicle. Recently tracking systems normally uses GPS[16] or GLONASS technique for finding the location of the vehicle. Vehicle data can be viewed on electrical map using the Internet or some other specialized application. Cities public transport authorities are an growing common users of tracking systems, particularly in large cities.

To carry out the tracking of the vehicle a GPS device is implanted into the vehicle . So how GPS enabled devices get[8][9][13] location through satellites, all these happening is based on the concept called Trilateration[10]. 


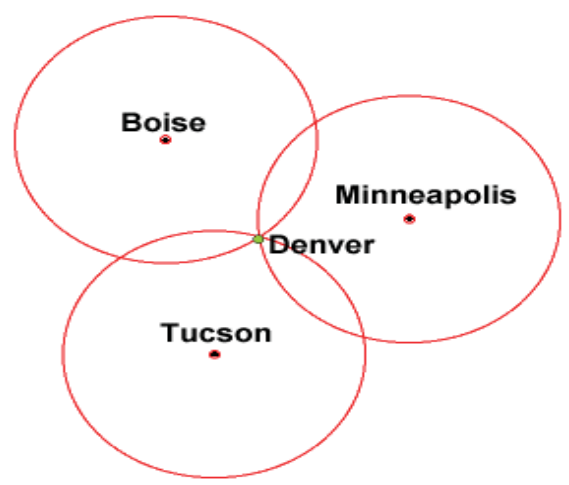

Fig.1. Locating GPS Device Using Trilateration

To locate an GPS[1][3][17] devices minimum three satellites are required and each satellite forms an radius of its reach and through these radius creates a sphere, the location at which sphere of each satellites collides is the actual locations of the GPS devices. In the above figure the location at which all point joins here it is Denver is the actual location of the GPS[4][7][14] device. Using this technique of trilateration tracking or locating of the vehicle is also carried out.

There are many different techniques are used worldwide which uses the vehicle tracking system techniques to locate the vehicles, fleets of an organization etc. This papers looks into many different types of techniques used worldwide to track the vehicles.

\section{RELATED WORK}

\section{A Tram Location and Route Navigation System using Smartphone}

This Project is Implemented in the Trams of Toyoma city of Tokoya, where each tram is provided with GPS enabled phones which gets there location through the satellite and sends it to the bunch of server i.e. information collection server, data storage server and information retrieval server and then the desired users device. This applications helps the users of the tram to avoid unnecessary waiting time at the stop as they can know the current location of the tram on their mobile application[12].

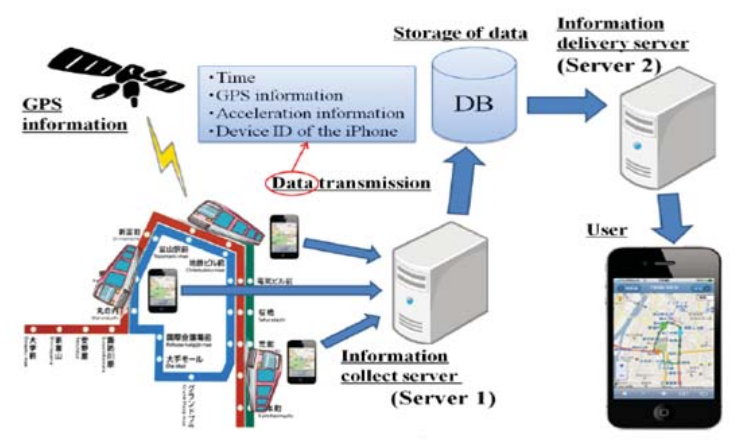

Fig. 2 Tram Location and Navigation System

\section{B. Tracking based on Velocity and Localization System using Smart phones with GPS and GPRS/3G}

This system uses the last location and the current location of the vehicle obtained by the GPS device to determine the Speed of the vehicle and sends vehicle information to the server using mobile GPRS/3G service, as the two coordinates are obtained means the last location and the current location of the device, the distance between two locations is determined and time taken to travel that distance, using both these data i.e. distance and time velocity is determined [1][15]. 


\section{A Novel Approach To Improve Vehicle Speed Estimation Using Smartphone’s INS/GPS Sensors}

This technique uses the accelerometer sensors as part of inertial navigation system (INS) provided in the smart phones to determine the speed of the vehicle and hence used for vehicle current real speed estimation, a new method of INS/GPS fusion is proposed which enhances the accuracy of speed estimation[2].

\section{Development and Design of GPS-GSM based tracking system with Google map based monitoring}

This Type of system used for vehicle tracking uses a GPS-GSM kit, which is implanted into the vehicle and locates the vehicle location using the GPS device in the kit and transfers the vehicle information to the servers using active GSM device in the kit and view the location of the vehicle on the Google Map provided in the system application or webpage[3].

\section{E. GPS and GPRS Based Cost Effective Human Tracking System Using Mobile Phones}

Here a simple approach is applied to track a person which is having a GPS enabled phone and active internet connection, the phone of person is provided with an specialized application which after collecting location information using GPS device in its phone sends it to the particular location where the persons location is requested[4].

\section{F. GPS - GSM Based Tracking System}

This Type of system used for vehicle tracking uses a GPS-GSM kit, which is implanted into the vehicle and locates the vehicle location using the GPS device present in the kit and transfers the vehicle information to the servers using the active GSM device in the kit, after the storing the information in the server, information is retrieved using application at particular location [7][11].

\section{G. Bus Locator via SMS Using Android Application}

This System uses an Android Phone having GPS facility with an specialized application implanted in the Bus, using this Android phone's GPS the location of the Bus is determined and this location is send to the requestor using specialized application in the phone present in the bus by cellular SMS service as an coordinates of the location[22].

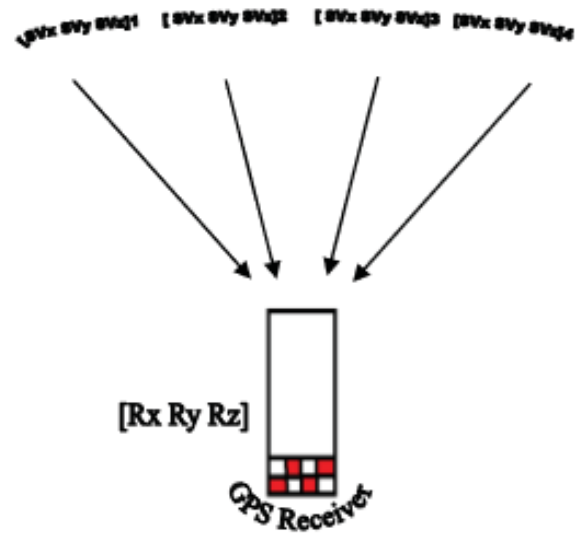

Fig. 3 GPS receiver tracking

\section{H. Estimating Bus Arrival Time on the Basis of Global Positioning System Data}

This system is used to determine the arrival time of the Bus to the particular Bus stop, here the current location of the bus is determined using the GPS device implanted into the Bus and distance is determined between the current location and the desired Bus stop and the speed of the bus is determined using GPS only by considering previous bus coordinates and by using those information i.e. distance and the speed the predicted arrival time of the Bus is determined to the particular desired Bus stop[19]. 


\section{PROPOSED IMPROVEMENTS}

As seen above this paper discuses many different techniques to track the vehicle but some of them have some drawbacks and some needs some enhancement or improvements. The table below discuses the Proposed Improvements needed in the above techniques so that they can become more efficient.

\begin{tabular}{|c|c|c|}
\hline & Techniques & Proposed Improvements \\
\hline A. & $\begin{array}{l}\text { Tram Location and } \\
\text { Route Navigation System } \\
\text { using Smartphone }\end{array}$ & $\begin{array}{l}\text { Instead of Using Multiple servers i.e. information } \\
\text { collection server, Data storage server and information } \\
\text { storage server, use of single server should be } \\
\text { implemented to reduce the cost. }\end{array}$ \\
\hline B. & $\begin{array}{l}\text { Tracking based on } \\
\text { Velocity } \quad \text { and } \\
\text { Localization System } \\
\text { using Smart phones with } \\
\text { GPS and GPRS/3G }\end{array}$ & $\begin{array}{l}\text { This system technique with further improvement can } \\
\text { be used to predict the exact arrival time of the vehicle } \\
\text { at the particular location by considering the distance } \\
\text { between the two coordinates as its current location and } \\
\text { other is desired location, and using these velocity and } \\
\text { the distance, the arrival time of the particular vehicle } \\
\text { can be determined at the particular location. }\end{array}$ \\
\hline $\mathrm{C}$. & $\begin{array}{l}\text { A Novel Approach To } \\
\text { Improve Vehicle Speed } \\
\text { Estimation } \quad \text { Using } \\
\text { Smartphone's INS/GPS } \\
\text { Sensors }\end{array}$ & $\begin{array}{l}\text { Using of GPS as a sensor for determining the speed, so } \\
\text { that low cost phones without accelerometers can also } \\
\text { be used. }\end{array}$ \\
\hline D. & $\begin{array}{l}\text { Development and Design } \\
\text { of GPS-GSM based } \\
\text { tracking system with } \\
\text { Google map based } \\
\text { monitoring }\end{array}$ & $\begin{array}{l}\text { Instead of using GSM-GPS kit use any mart phone } \\
\text { with GPS enabled, which would be more useful and } \\
\text { cost efficient as now most of the population are having } \\
\text { smart phones with them. }\end{array}$ \\
\hline E. & $\begin{array}{l}\text { GPS and GPRS Based } \\
\text { Cost Effective Human } \\
\text { Tracking System Using } \\
\text { Mobile Phones }\end{array}$ & $\begin{array}{l}\text { This technique of tracking humans using smart phones } \\
\text { with specialized application can be used for tracking of } \\
\text { public transportation vehicles also. }\end{array}$ \\
\hline F. & $\begin{array}{l}\text { GPS - GSM Based } \\
\text { Tracking System }\end{array}$ & $\begin{array}{l}\text { Instead of using GSM-GPS kit use any mart phone } \\
\text { with GPS enabled, which would be more useful and } \\
\text { cost efficient as now most of the population are having } \\
\text { smart phones with them. }\end{array}$ \\
\hline G. & $\begin{array}{l}\text { Bus Locator via SMS } \\
\text { Using } \\
\text { Application }\end{array}$ & $\begin{array}{l}\text { Instead of using SMS service to send location } \\
\text { coordinates to the other end which is not cost } \\
\text { benefited, use of internet service is to be used so that it } \\
\text { will not cost separately for each SMS and will be more } \\
\text { cost benefited. }\end{array}$ \\
\hline $\mathrm{H}$. & $\begin{array}{l}\text { Estimating Bus Arrival } \\
\text { Time on the Basis of } \\
\text { Global Positioning } \\
\text { System Data }\end{array}$ & $\begin{array}{l}\text { Instead of using single data for predicting speed, a } \\
\text { bunch of historical data is also to be considered so that } \\
\text { arrival time of the vehicle will be more precise and } \\
\text { accurate while considering Environmental conditions. }\end{array}$ \\
\hline
\end{tabular}

\section{PROPOSED FUTURE DEVELOPMENT}

The Proposed Future Development should be a system for the public transportation vehicles like Buses that each bus should have a GPS enabled device[6] implanted into it and the arrival time of each Bus should be determined at each Bus stop considering all Environmental Conditions like rains, fog, traffic jam etc. and it also should provide information to the public like speed of the bus, current location of the bus on the map, distance from the desired bus stop, delay from the predefined time etc.

The Proposed system Architecture is supposed to be like below diagram. 


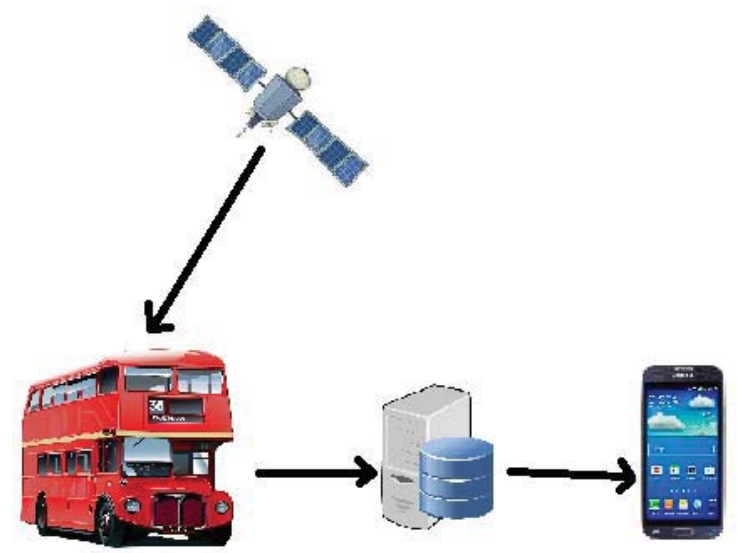

Fig. 4. Architecture of the proposed system

This complete system should be based on the four important modules :-

1) Satellite :- Satellites forms the trilateration and finds the coordinates of the vehicle on the map.

2) GPS enabled device in the vehicle :- This GPS[2][5][18] enabled device will be in the vehicle and sends its location coordinates to the server using specialized application.

3) Server :- The Server process all the data sent by the GPS device in the vehicle and send the required query results to the users phone application who wanted to know the information regarding the bus like its current location or its exact real arrival time at the particular bus stop.

4) User phone with Application :- Users will be having phone which is enabled with an application which gets all the information regarding vehicles timing which is obtained by the server.

Proposed Algorithm for Estimating Arrival time is shown below :-

1) Get the Location of the User using coordinates given by the satellites.

2) Get the Location of the Vehicle using coordinates given by the satellites.

3) Using 1) and 2) Calculate the Distance between user and the current position of the Vehicle.

4) Calculate the speed of the required bus considering the current stop and the previous stop.

$$
\mathrm{Sr}=\mathrm{d} 1 / \mathrm{t} 1
$$

5) Get the historical data i.e. speed of the buses along that path considering for a interval of particular time period let say last 30 minutes, and take the average of the speed of the buses.

$$
\mathrm{S}=\mathrm{d} / \mathrm{t}
$$

6) Then the Calculate the predicted speed of the required bus along the required path by considering (1) and (2).

$$
\mathrm{Sp}=(\mathrm{Sr}+\mathrm{S}) / 2
$$

7) If no Bus has passed between the given time period then calculate the predicated speed using step 1) and equation (1). 
8) Then Calculate the Estimated Arrival time (ETA) of the bus at the particular stop using equation (3) and distance between bus current location and the user current location i.e. d.

$$
\mathrm{ETA}=\mathrm{Sp} / \mathrm{d}
$$

\section{CONCLUSION}

This paper studies Different type of vehicle tracking system along with their future needed improvements and this paper also proposes a typical system for the public transports like bus which can determine the exact arrival time of the bus at the particular bus stop considering all environmental conditions taking into account all the drawbacks and needed improvements in the above discussed systems.

\section{REFERENCES}

[1] Velocity based Tracking and Localization System using Smartphones with GPS and GPRS/3G Ibrahim Abdallah Hag Eltoum, Mohammed Bouhorma August 2013.

[2] A Novel Approach To Improve Vehicle Speed Estimation Using Smartphone's INS/GPS Sensors Arijit Chowdhury, Tapas Chakravarty, P. Balamuralidhar September 2014.

[3] Design and Development of GPS-GSM based tracking system with Google map based monitoring. Pankaj Verma 1, J.S Bhatia 2.

[4] GPS and GPRS Based Cost Effective Human Tracking System Using Mobile Phones Ruchika Gupta and BVR Reddy.

[5] GPS Based Low Cost Intelligent Vehicle Tracking System (IVTS) Dr. Kamal Jain1 and Rahul Goel2 2012.

[6] Mobile Tracking Application for Locating Friends using LBS Abhijeet Tekawade1, Ahemad Tutake2, Ravindra Shinde3, Pranay Dhole4, Mr. Sumit Hirve5 April 2013.

[7] GPS - GSM Based Tracking System Abid khan\#1, Ravi Mishra*2 2012.

[8] Design and Implementation of Web-Based GPS-GPRS Vehicle Tracking System Dr. Khalifa A. Salim\#1, Ibrahim Mohammed Idrees\#2 December 2013.

[9] Hybrid GPS-GSM Localization of Automobile Tracking System Mohammad A. Al-Khedher December 2011.

[10] A novel and cost effective approach to public vehicle tracking system. Deepak Mishra1, Apurv Vasal2, Puneet Tandon1 January 2012.

[11] Smart Onboard Public Information System using GPS \& GSM Integration for Public Transport Mr. Prafull D. Patinge1, Ms. N. R. Kolhare2 July 2012.

[12] Tram Location and Route Navigation System using Smartphone Kunimitsu Fujita, Masaya Kato, Tatsuya Furukane, Keiji Shibata, Yuukou Horita, Member, IEEE 2012.

[13] Real Time Vehicle Locking and Tracking System using GSM and GPS Technology-An Anti-theft System Pravada P. Wankhade1 and Prof. S.O. Dahad2 March 2011.

[14] Vehicle Tracking and Locking System Based on GSM and GPS R.Ramani1, S.Valarmathy1, Dr. N.SuthanthiraVanitha1, S.Selvaraju2, M.Thiruppathi 2, R.Thangam3 August 2013.

[15] Positioning and Navigation system using GPS, J.Parthasarathy 2006.

[16] Global positioning system Yutaka Masumoto 1993.

[17] Vehicle tracking system employing global positioning system (GPS) satellites Alison K. Brown, Mark A. Sturza 1993.

[18] Vehicle locating system utilizing global positioning Gustavo G. Suarez, Carlos S. Baradello, Salvador Sibecas July 1999.

[19] Predicting Bus Arrival Time on the Basis of Global Positioning System Data Dihua Sun, Hong Luo, Liping Fu, Weining Liu, Xiaoyong Liao, and Min Zhao.

[20] Vehicle tracking system Eliezer A. Sheffer, Marco J. Thompson June 1993.

[21] Online Bus Arrival Time Prediction Using Hybrid Neural Network and Kalman filter Techniques M. Zaki, I. Ashour, M. Zorkany, B. Hesham.

[22] Bus Locator via SMS Using Android Application Karan Punjabi, Pooja Bolaj, Pratibha Mantur, Sneha Wali. 